\title{
Design, Assembly and Testing of HVAC Electrical Panel
}

\author{
Harshil Thakkar, Utsav Patel, Naineel Suthar \\ B. Tech Student: \\ Dept. of Electrical Engineering \\ Indus University \\ Ahmedabad, Gujarat, India
}

\author{
Prof. Kaushal Patel \\ Assistant Professor: \\ Dept. of Electrical Engineering \\ Indus University \\ Ahmedabad, Gujarat, India
}

\begin{abstract}
This paper describes the basic concepts of the design, assembly, and testing of HVAC electrical panels. Here are the complete details about components that are used in designing of HVAC panel. HVAC panel designing consists of designing of GA drawing of the panel, designing of a power circuit for the HVAC system, and designing of a control circuit of the HVAC system. After considering different parameters, the assembly will cover up as per the guidelines and requirements of the consumer.
\end{abstract}

Keywords-Importance; components; GA diagram; power wiring; control wiring; assembly; testing.

\section{INTRODUCTION}

The HVAC control panel includes the control of temperature, humidity, and airflow in a particular space. For this control, the panel has a different part to control these factors. The heating, ventilation, and air-conditioning (HVAC) system is a complex system installed in a building. A right-sized HVAC system will provide the desired comfort and also it will run efficiently. Right-sizing the HVAC system starts with an accurate understanding of the heating and cooling loads on a space. A full HVAC design involves more than a load estimate calculation. The load calculation is the first step of the HVAC design procedure. This strategy guideline discusses the information needed to design the air distribution system to deliver the proper amount of conditioned air to space. The equipment selection and the air distribution design are based upon the loads and each other. And the heating and cooling loads are dependent upon the building location and the construction of the house.

\section{A. Importance of a Control System}

- Maintain thermal comfort conditions

- Maintain optimum indoor air quality

- $\quad$ Reduce energy use

- Safe plant operation

- To reduce manpower costs

- Identify maintenance problems

- Efficient plant operation to match the load

- Monitoring system performance

\section{GENERAL OVERVIEW}

AHU system is an environmental control system. This system includes the control of temperature, humidity, and airflow in a particular space. Primary AHU equipment includes heating equipment, ventilation equipment, and cooling or air-conditioning equipment. AHU system is used in different types of buildings. For example, industrial, commercial, residential and institutional buildings. The aim of the AHU system is to satisfy the thermal comfort of the building. The system adjusts or changes the outdoor air conditions to the desired condition.

AHU system consists of heater bank, condenser, fan, filers, mixing box, humidifier, and dehumidifier, etc. Our HVAC electrical panel is connected with heater bank load, fans motor and condenser. Now Let's see components of the HVAC electrical panel below.

\section{COMPONENTS OF ELECRICAL PANEL}

\begin{tabular}{|l|l|l|l|}
\hline component & $\begin{array}{l}\text { No of } \\
\text { component }\end{array}$ & TYPE & $\begin{array}{l}\text { Rating } \\
\text { (Amp. / } \\
\text { vol })\end{array}$ \\
\hline DISCONNECTOR & 1 & TPN & $32 \mathrm{~A}$ \\
\hline FUSE LINK & 3 & HRC & $32 \mathrm{~A}$ \\
\hline MCB & 6 & SP & $6 \mathrm{~A}$ \\
\hline MCB & 1 & TP & $16 \mathrm{~A}$ \\
\hline MCB & 1 & TPN & $25 \mathrm{~A}$ \\
\hline CONTACTOR & 2 & $1 \mathrm{NO}$ & $9 \mathrm{~A}$ \\
\hline AUX. RELAY & 1 & $4 \mathrm{CO}$ & $230 \mathrm{~V}$ \\
\hline PANEL FAN & 1 & & $230 \mathrm{~V}$ \\
\hline $\begin{array}{l}\text { INDICATING } \\
\text { LAMP }\end{array}$ & 6 & & $240 \mathrm{~V}$ \\
\hline PUSH BUTTON & 1 & & $230 \mathrm{~V}$ \\
\hline PUSH BUTTON & 1 & NO & $230 \mathrm{~V}$ \\
\hline VFD & 1 & NC & $415 \mathrm{~V}$ \\
\hline SMPS & 1 & & $230 \mathrm{~V}-24 \mathrm{v}$ \\
dc
\end{tabular}

\section{A. Disconnector}

Main disconnector is used to isolate the whole panel circuit from a single place. This Isolator is attached at the beginning of the panel. 


\section{B. Fuse link}

A fuse is an electrical device used for protecting electrical equipment and cables from overcurrent damage. Different types of fuses are used in different electrical panels. The main types of fuses used in panels are HRC fuse and Cartridge fuse.

\section{C. $M C B$}

MCB (Miniature Circuit Breaker) is a switching device that is capable of protecting the distribution line or feeder connected to it from overloads and faults. If a circuit overload, the mechanism inside the MCB trips the switch and breaks the continuous circuit.

\section{Contactor}

The contactor is used in every motor control panel. The contactor is a high-power application switching device. It is one type of relay. It consists of normally open contact and auxiliary contact points. The current rating of the contactor is dependent on the categories of the contactor.

\section{E. Auxiliary relay}

This allows control over the breaker remotely of automatically apply or remove power from a load

\section{F. Panel fan}

A small cooling fan is provided in Panel. This fan provides sufficient cooling to the equipment.

\section{G. Indicating lamp}

Different Indicators are used in the HVAC panel. Indicators for START, STOP, TRIP, FIRE DAMPER, AHU DOOR OPEN, etc.

\section{H. Push button}

There are two different contacts NO and NC. They are used in the control circuit of HVAC panel design. NO contacts are normally open contact and NC contacts are normally close contact.

\section{I. $V F D$}

VFD used in HVAC panel for smooth motor control and to limit the starting inrush current. VFD consists of Rectifier, DC link, and Inverter. The rectifier converts AC voltage to DC, DC link does smoothen of DC pulses and Inverter converts this $\mathrm{DC}$ voltage to $\mathrm{AC}$ voltage. This output $\mathrm{AC}$ voltage is variable frequency $\mathrm{AC}$ voltage as per parameter set on VFD equipment

\section{J. SMPS}

Switch-mode power supplies, SMPS provides improved efficiency \& space-saving over traditional linear supplies. It is mainly used in the panel for converting AC voltage to the required DC voltage signal. SMPS provides required DC voltage to the programmable controller.

\section{K. Controller}

The programmable controller is a predefined coded controller. AHU temperature and humidity parameter can be set in this controller. This gives the command to the control circuit when the temperature or humidity will become above or under the set Parameters.

\section{Sensor}

Temperature and humidity sensors $(\mathrm{T}+\mathrm{Rh})$ are used for sensing temperature and humidity respectively in AHU units.

\section{GA DIAGRAM OF HVAC PANEL}

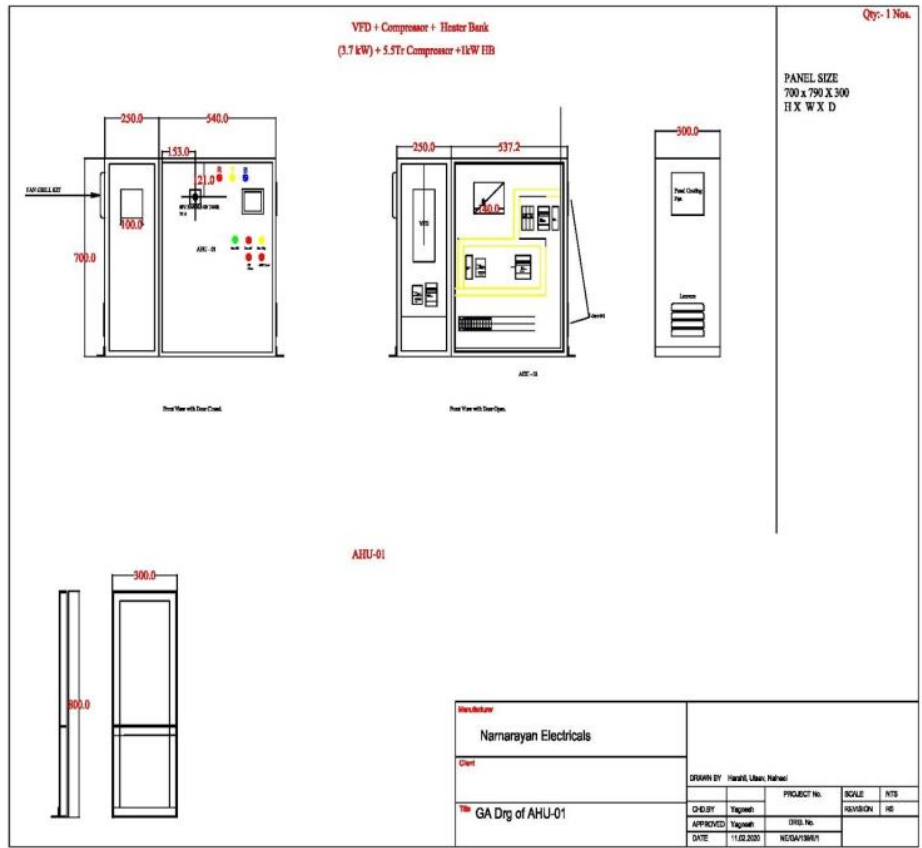

Fig. 1. GA Diagram

The designing is the first step of the production of the panel for designing there are some components that are necessary for it the following are as below: -

$>$ The requirement sent by the receiver of the panel

$>$ The single line diagram including incoming line outgoing line for the applications

$>$ The make list for the components to be used

$>$ The rating of the I/P lines and the applications

During this project, we measure the different parameters (length, width, height) of panel and pieces of equipment. By using these parameters, we made a Geographical Arrangement diagram of the HVAC panel.

It refers to the location of different equipment and assemblies within the overall design of the electrical panel. It is a schematic representation of physical electrical panel design.

\section{POWER CIRCUIT}

Power circuits mainly use for providing power with protection. In the power circuit, there is 3 phase 4 wire system with earth ground. AHU Fan Motor, Condensing Unit, And Heater Bank are calculated as a load of HVAC panel. VFD use for better speed regulation and smooth starting of AHU Fan Motor. The Main supply is driven from the Main distribution Panel with 415 v.

As shown in Fig 2.0 the main power supply from the HVAC distribution panel and it will distribute in three main loads of HVAC electrical panel. The power circuit isolated 
with the Fuse base Disconnector as mounted at the incomer of the panel. After that, it is connected with the indication LAMP which indicates the presence of all phases with the protection of single-pole MCB at sub-incomer. From the incomer, 3 Phase will directly be Connected to the terminal of VFD as L1, L2, L3 with the protection of three-pole MCB at sub-incomer. From the o/p terminal of VFD as U, V, W phase will pass from the Contactor K1. After passing from the contactor $\mathrm{K} 1,3 \mathrm{ph}$ directly connects to the terminal box TB1. The load that will connect with the TB1 is AHU Fan Motor.

As a parallel, 3 Phase with neutral wire will directly be Connected to the terminal box TB1 with the protection of four-pole MCB at sub-incomer. The load will connect with the TB1 is Compressor.

As shown in fig 2.0 from the incomer, 3 Phase with neutral wire will directly pass from The Contactor K2 with the protection of single-pole MCB at sub-incomer. After passing from the contactor $\mathrm{K} 2,3 \mathrm{ph}$ directly connect to the terminal box TB1. The load that will connect with the TB1 is Heater Bank.

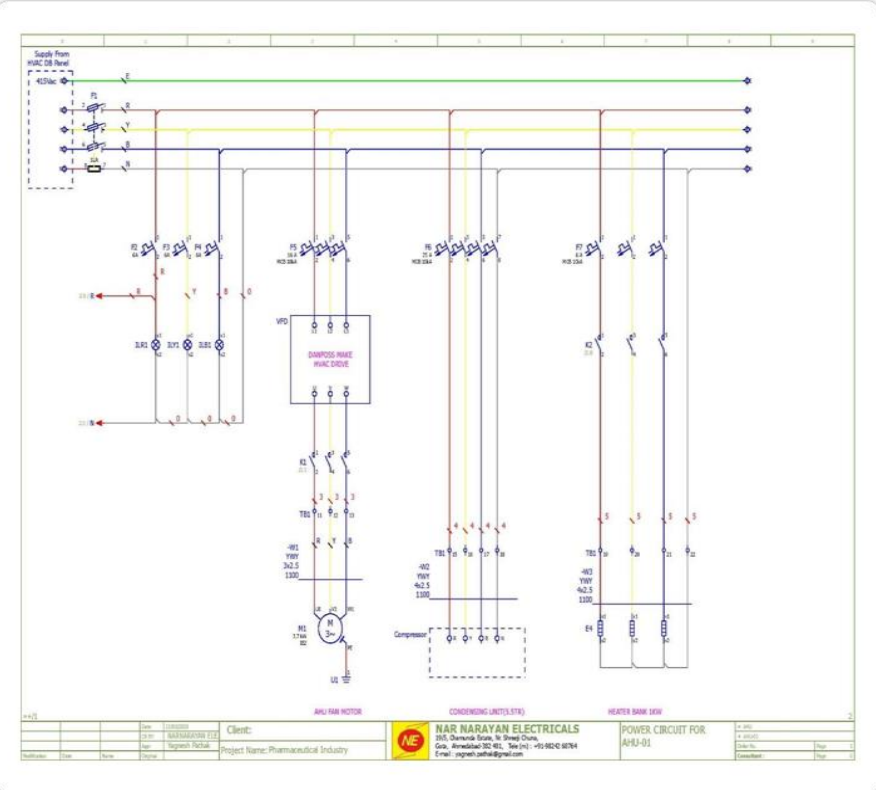

Fig. 2. MLD of Power Circuit

\section{CONTROL CIRCUIT}

Control Circuit mainly use for control or providing the signal to the power circuit to operate the machine as per the demand required. However, For the HVAC panel temperature and humidity are the main functions for control and stabilize the atmosphere of the operation room or area. Moreover, to senses the temperature and humidity and as per the measures to provide the signals to the power circuit there are sensors and programable controllers that are additionally used for this co-ordination. Whereas, limit switches are also used in the control circuit to release the signals which are explained in further explanations.

As shown in Fig 3.0, R-Ph is connected to the limit-switch LS1 of AHU door. Now if the door will open then the circuit will not be completed and the indicator of the AHU door will indicate that the door of the AHU machine is open. After that, it is connected to the limit-switch LS2, which is provided at the fire damper. if the fire will be Done in the system then limit switch release the signals and incomplete the power circuit for safety purpose. Moreover, AHU door will close and no fire symptoms will Show then the circuit will complete and it will give the supply to the VFD's control terminals.

There is two Relay available for auxiliary contact. Power has given in the common contact of both Relay. Both Relay has one NO and NC contact. AHU Fan Trip indicator will connect through the NO terminal of Relay 1. While DOL Starter with auxiliary Relay will connect through the NC contact of Relay 1. The DOL starter for AHU Fan Motor with the help of auxiliary Relay and smooth starting through the VFD. Moreover, in fault condition trip signal will terminate by the co-ordination of VFD's Relay.

As the START signal will release by the START button the Auxiliary Relay will be energized and the NO contact of Relay will close and the signal will release to the Relay 2 of VFD and the NO contact will close. As of NO contact of Relay 2 will close the supply will energize the Contactor K1 and the AHU Fan motor will start with the nominal speed as the program via VFD.

Furthermore, The $\mathrm{R}$ phase passes through the auxiliary contact $\mathrm{NO}$ of contactor $\mathrm{K} 1$. As of contactor, K1 energizes NO contact will close and the supply passes through the contact and the Panel cooling Fan will ON and also AHU FAN ON indicator will indicate that motor is ON. Moreover, supply passes through the SMPS which converts the power into DC Supply and it will give to the programmable controller which gives the signal to the heater bank and compressor for the temperature and humidity control for operational area or room. The temperature and humidity were measured through the temperature sensor and humidity sensor which are connected to the programmable controller. The programmable controller will measure the result of the sensor and convert it into the digital signal.

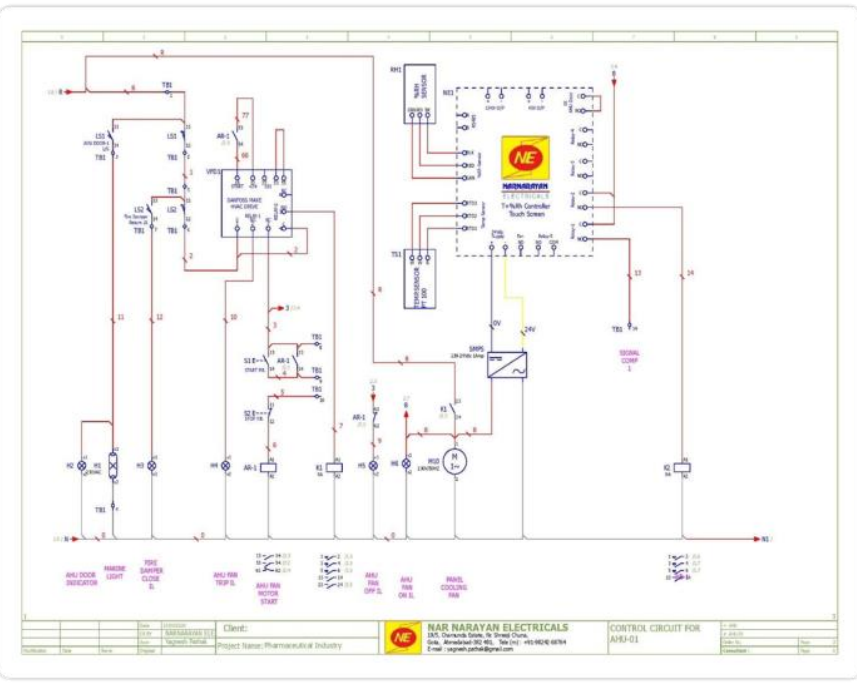

Fig. 3. Control Circuit Diagram 


\section{ASSEMBLY OF PANEL}

\section{A. Required accessories for assembly}

- Nut and bolt

- Push button

- Controller

- Indication lamp

- Cable ties

- Cable gland plate

- Cable lugs

- Panel lock

- Rail channel

- PVC wire duct

- Panel fan

- Terminal blocks

- Ferrule

\section{B. As the given steps are considered for the assembly}

$>$ As per the general assessment, panel enclosure will design for assemble with the finishing of powder coating

$>$ Take the measurements and marking on panel board for punching the hole via drill machine and as required cut the PVC wire duct and Rail channel for assemble the electrical components

$>$ Assemble the PVC wire duct and Rail channel with nut and bolt on panel board

$>$ Assemble the number of terminal blocks, MCB, auxiliary relay, contactor on the Rail channel

$>$ The second part for fabrication and assemble in panel enclosure is panel door where indication lamp, push button, controller, panel lock, SFU handle, etc are mounted on the enclosure door

$>$ Panel fan assembles as GA drawing of panel enclosure for cooling purpose.

Checking the tightness of the all the assemble parts

\section{Wiring}

The wiring is the most important part of the panel because the control of the panel and power transmission is also done through wire. The control wiring is usually done with $2.5 \mathrm{Sq}$. $\mathrm{mm}$ copper wire or the $1.5 \mathrm{Sq}$. $\mathrm{mm}$ copper wire. We have to draw the wire as per the designed diagram in the panel and select the wire as specified by the designer. Cable tie will use for making a bunch of wire.

Given points are consider during wiring.

$>$ Select the type of wire and gauge of wire as per requirement

$>$ RED, YELLOW, BLUE colours are considered for power wiring and grey colour for control wiring

$>$ Measurement for wiring and cut the wire as per measurements

$>$ Fix the lug and ferrule on wire for wire indication

$>$ Follow BS7671/ IET wiring regulation

$>$ Follow company standards and procedures

\section{TESTING}

At the end of the panel, fabrication is to check the panel meets the requirement of the consumer. There is some test list below for checking the quality, electrical, and logic for the panel after the process of assembly is been completed.

\section{A. Quality checks}

$>$ Verification of material as per approved GA drawing

$>$ Overall dimensions as per approved GA drawing

$>$ Tightness of wire connection and pull test of crimping of lugs (on random basis)

$>$ Ensuring enclosure is free of debris

\section{B. Electrical checks}

$>$ Earth continuity / earthing system

$>$ Wiring check as per control and power wiring diagram

$>$ Phase sequence / Polarity check

$>$ Polarity

$>$ Insulation resistance

\section{Logic test}

HVAC panel mainly uses for $\mathrm{T}+\mathrm{Rh}$ control for room or area via AHU machine. For this control, we need to provide logic from programmable controller. In this test, we set the different logics in the controller via set the parameter of temperature and humidity. The different logic for the operation is given below.

\begin{tabular}{|l|l|l|l|}
\hline Temperature(T) & $\begin{array}{l}\text { Humidity } \\
\text { (Rh) }\end{array}$ & condenser & $\begin{array}{l}\text { Heater } \\
\text { Bank }\end{array}$ \\
\hline High & High & ON & OFF \\
\hline High & Low & ON & OFF \\
\hline Low & High & ON & ON \\
\hline Low & Low & OFF & ON \\
\hline
\end{tabular}

(Above temperature and humidity data are compared w.r.t set parameters in the controller)

\section{CONCLUSION}

This paper describes the process of designing of the electrical panel for the HVAC system. This paper describes how the actual panel works from the power circuit diagram and control circuit diagram. We can build this type of HVAC panel design according to the requirement.

\section{ACKNOWLEDGEMENT}

The developed HVAC electrical panel is effectively applicable for air handling unit to achieve comfortable atmosphere Facilities for buildings of factories. This electrical panel has controller and sensors for provide building management system as per consumer's requirements. We like to appreciate the support provided by our faculty guide and our host company "Narnarayan electricals" to provide technical support. 


\section{REFERENCES}

[1] KMC Controls. "Understanding Building Automation and Control Systems". Archived from the original on 19 May 2013. Retrieved 27 March 2013.

[2] Narnarayan electricals. Manufacturer of electrical control panel. Technical support for designing

[3] L. Pérez-Lombard, J. Ortiz, and C. Pout, "A review on buildings energy consumption information," Energy Build., vol. 40, no. 3, pp. 394-398, 2008.

[4] A. Bhatia, "Basic Electrical Engineering for HVAC Engineers."

[5] "Building environment standards". www.iso.org. Retrieved 2011-0514.

[6] "Building environment design-Indoor environment-General principles". Retrieved 14 May 2011.

[7] Refrigeration and HVAC Electricity Fundamentals., ISBN 978-289640-714-9 (Printed version)

[8] "MANUFACTURING ELECTRICAL AND PLC PANEL BOARD", NIC Code: 27104 